\title{
FACULTY PERSPECTIVE ABOUT DIFFICULTIES IN IMPLEMENTATION OF NEWLY INTRODUCED INTEGRATED CURRICULUM FOR BASIC SCIENCES IN KING EDWARD MEDICAL UNIVERSITY
}

\author{
Khalid Mahmood Cheema \\ King Edward Medical University, Lahore Pakistan
}

\begin{abstract}
Objective: To explore the perceptions of basic sciences faculty about the integrated curriculum. Study Design: Sequential mixed method study.

Place and Duration of Study: King Edward Medical University Lahore, from Oct to Dec 2017.

Methodology: A 15-item survey was utilized as quantitative information collection device that gave the numerical depiction of the patterns, views or conclusions of the participants. In-depth interviews were done after survey as a tool of qualitative data collection to investigate beliefs and explore the attitudes.

Results: All ninety three faculty members of basic sciences in medical college were contacted and survey response rate was $96.77 \%$ (90/93). $97 \%$ of faculty members had awareness about curricular integration; but majority (56\%) had concerns about its appropriate implementation. Majority agreed that integration was beneficial for students' learning. They were satisfied with its design and relevance. Major considerations were correct implementation and lack of coaching in adopting new teaching methods and educational approaches.

Conclusion: Curriculum integration is useful and essential in student's learning but training is necessary in its planning and execution. Current negative perceptions need to be addressed through further research.
\end{abstract}

Keywords: Curriculum integration, Perceptions, Student-centered learning.

This is an Open Access article distributed under the terms of the Creative Commons Attribution License (https://creativecommons.org/licenses/by-nc/4.0/), which permits unrestricted use, distribution, and reproduction in any medium, provided the original work is properly cited.

\section{INTRODUCTION}

The process of curricular integration is well under way in medical teaching institutions all over the world ${ }^{1}$. Integrated curriculum in basic sciences is a deliberately structured curriculum to organize or facilitate learning across the basic science disciplines around key concepts, themes or problems. Many of these changes focus on horizontal and/or vertical integration of the curriculum. Horizontal integration combines either related disciplines of basic science to improve understanding of body systems or related medical sciences among students through interdisciplinary clerkships; while Vertical integration concerns either the inclusion of clinical experience in the early part of the curriculum or the reintroduction of basic science content in clinical years.

Curricular integration is a complex process and poses a challenge to the faculty. It can refer to teaching process, content, faculty function or knowledge integration within student's minds ${ }^{2}$. It can happen at various rates and a few subjects are incorporated more effectively than others ${ }^{2}$. Faculty has a pivotal role in effective implementation of an integrated curriculum. Their understanding of integration is evident in everyday

Correspondence: Dr Khalid Mehmood Cheema, Associate Professor of Surgery, King Edward Medical College, Lahore Pakistan

Received: 25 Nov 2019; revised received: 21 Mar 2020; accepted: 08 Apr 2020 teaching and learning activities ${ }^{3}$. Actual integration occurs at the level of teaching sessions in the classroom and its success depends upon the choices made by the individual faculty members present at that time ${ }^{4}$. Hence recognition of individual and collective faculty concerns during the change process is of utmost importance.

Integrated program has been practiced in many organizations around the world since the $1950 \mathrm{~s}^{5}$. In regional countries such as India and Nepal, integrated curriculum is also followed. Studies of medical teachers' perceptions have concluded that teachers agree to implement these curriculum reforms ${ }^{6}$. Integrated modular curriculum is a relatively new concept that began as a pilot project in 2001 with the assistance of the WHO in four medical colleges in Pakistan ${ }^{7}$. Medical teachers identified some areas of concern during its implementation. They included need of infrastructure, financial support, and political back. There does not appear to be any disagreement on integration, but best models of integration and practical challenges in integrated curricula are troublesome areas that require further research and development ${ }^{8}$.

There are many studies that report student's views and opinions regarding integrated medical curricula ${ }^{9}$, but a few number of studies discussed perceptions of horizontal and vertical integration in the 
faculty. Evidence proposes that instructors concur for updating themselves towards new patterns and trends within the field of medical education ${ }^{10}$. To recognize obstacles to integration and potential new approaches to encourage integrated curricula, the present study asked basic sciences faculty about their perceptions towards integration.

\section{METHODOLOGY}

A sequential mixed method study was done at King Edward Medical University from October 2017 to December 2017. Ethical approval was provided by the Institutional Review Board of the University (No.188/ RC/KEMU, dated 6.10.2017). As per PMDC requirements, modular system is implemented recently in our medical college as part of integrated curriculum.

Around ninety three members of basic sciences faculty working in King Edward Medical College participated in the study after taking their informed consent. Participants were selected and enrolled on deliberate premise by non-probability purposive sampling. Twelve faculty members were selected for interviews.

A questionnaire based survey was used to collect quantitative data, followed by interviews for qualitative data. A 15-items self-administered rating scale questionnaire was designed to measure the faculty's impressions of an integrated curriculum. A pilot study on 20 faculty members was done before the questionnaire was administered to all faculty of basic sciences which offered a quantitative overview of participants' patterns, attitudes or perceptions. Interviews were used to investigate perceptions and attitudes as a qualitative tool. Interviews therefore explored the difficulties in implementing our institution's integrated curriculum and how these barriers can be overcome with possible workable solutions. All interviews were audio recorded and transcribed for further analysis. Openended questions were designed to gather views and perceptions about the integration of various disciplines. Importantly, interviews and observations have been made anonymous.Items related to the perception of faculty on various aspects of integration were selfreported on a 5-point Likert scale, ranging from $1=$ strongly disagree to $5=$ strongly agree.

Questionnaires were distributed to faculty members and were recollected back after 2 or 3 days. For qualitative data collection, interview sessions were conducted for twelve participants. A semi-structured interview format was used by investigator for conducting interview sessions. Every session lasted about 20 minutes. There was no monetary incentive. The session was audio-taped with backup facility and transcripts were made to record accurate information provided.

Quantitative data from questionnaires was analyzed by using the statistical programme SPSS version 24 . Descriptive statistics analysis was done for the variation. Statistical analysis included frequencies, and descriptive statistics including means with standard deviations. Based on the statistical results, final explanations were made. The qualitative interview data were analyzed by identifying themes and subthemes that emerged through the analysis of their interviews. The open-ended questions were semi quantitatively analyzed to recognize shared designs or themes communicated by the participants during the design, development, delivery, and evaluation of the integrated curriculum. This was followed by the themes (or perspectives) analysis, the formation of ties between the themes, the explanation of how these themes arose and finally the generation of conclusions. The argument was backed by direct quotes to explain the various ways and conclusion was drawn by triangulation of quantitative and qualitative data.

\section{RESULTS}

A total of 93 faculty members participated in the study. Respondents' demographic information (i.e., positions and work departments) was presented in table-I. The largest percentage of respondents was demonstrators $(55.9 \%)$ while the largest respondents belong to Anatomy (21.5\%) and Physiology Department (21.5\%).

Faculty members were asked about their general perceptions of the impact of curricular integration. Eighty-two percent of respondents agreed/strongly agreed that curricular integration resulted in learning experiences that were more relevant and engaging while facilitating higher-order learning. Seventy-six percent of respondents agreed or strongly agreed that the planning and design of integrated courses involved cooperation between the faculty of basic and clinical sciences members. However at the same time only $34 \%$ reported that integrated curriculum was being implemented appropriately. Fifty-four percent of the respondents indicated that contact hour distribution of basic sciences was adequate to ensure depth and breadth of each component of the integrated course. Rest of the details are shown in table-II.

Analysis of data after transcription revealed some common words and sentences used by faculty members during interviews. Themes and sub-themes after qualitative data analysis for teachers were shown in 
table-III \& IV. The major emerged themes included, "Designing the integrated curriculum", "Integrated integration" and "Using student-centered instructional curriculum implementation", Obstacles to curricular

Table-I: Respondent demographics.

\begin{tabular}{|c|c|c|c|c|c|}
\hline & \multicolumn{3}{|c|}{ Cadre } & \multirow{2}{*}{ Total } & \multirow{2}{*}{ Percentage } \\
\hline & Professor (HOD) & Associate Professor (AP) & Demonstrator & & \\
\hline Anatomy Department & 1 & 6 & 13 & 20 & 21.5 \\
\hline Physiology Department & 1 & 12 & 7 & 20 & 21.5 \\
\hline Biochemistry Department & 1 & 5 & 7 & 13 & 14.0 \\
\hline Medicine Department & 0 & 3 & 12 & 15 & 16.1 \\
\hline Pathology Department & 1 & 11 & 13 & 25 & 26.9 \\
\hline Total & 4 & 37 & 52 & 93 & 100 \\
\hline Percentage & 4.3 & 39.8 & 55.9 & 100 & - \\
\hline
\end{tabular}

Table-II: Teachers' details regarding integrated curriculum.

\begin{tabular}{l|c}
\hline Variable & Mean Score \pm SD \\
\hline Integrated Curriculum awareness & $4.71 \pm 0.56$ \\
\hline Integrated Curriculumis implemented appropriately & $1.70 \pm 0.69$ \\
\hline Integrated Curriculum design is satisfactory & $3.76 \pm 0.67$ \\
\hline Integrated Curriculum has adequate distribution of basic sciences & $2.71 \pm 0.59$ \\
\hline Integrated Curriculum results in relevant learning & $4.08 \pm 0.49$ \\
\hline Integrated Curriculum integrates skills and knowledge & $4.16 \pm 0.57$ \\
\hline Integrated Curriculum has better assessment system & $3.69 \pm 0.62$ \\
\hline Integrated Curriculum facilitates higher order learning & $4.41 \pm 0.51$ \\
\hline Integrated Curriculum engage students in learning & $4.56 \pm 0.47$ \\
\hline Integrated Curriculum helps in rectifying misconception & $3.10 \pm 0.51$ \\
\hline Integrated Curriculum emphasizes cooperation and collaboration & $3.96 \pm 0.35$ \\
\hline Integrated Curriculum promotes critical \& creative thinking & $4.44 \pm 0.54$ \\
\hline Integrated Curriculum provides opportunities to experience learning as a meaningful whole & $3.97 \pm 0.58$ \\
\hline Integrated Curriculum is more student-centered & $3.71 \pm 0.58$ \\
\hline
\end{tabular}

Table-III: Major themes and sub-themes.

\begin{tabular}{|c|c|}
\hline Themes & Sub-themes \\
\hline $\begin{array}{l}\text { Designing the } \\
\text { integrated } \\
\text { curriculum }\end{array}$ & $\begin{array}{l}\text { Defining curricular integration. } \\
\text { Curriculum planning. } \\
\text { Awareness level. } \\
\text { Institutional requirement. }\end{array}$ \\
\hline $\begin{array}{l}\text { Integrated } \\
\text { curriculum } \\
\text { implementation }\end{array}$ & $\begin{array}{l}\text { Resources. } \\
\text { Collaboration \& coordination between } \\
\text { disciplines . } \\
\text { Problem solving approach. } \\
\text { Relate classroom learning to real } \\
\text { world. }\end{array}$ \\
\hline $\begin{array}{l}\text { Obstacles to } \\
\text { curricular } \\
\text { integration }\end{array}$ & $\begin{array}{l}\text { Faculty resistance. } \\
\text { Crossing of disciplinary boundaries. } \\
\text { Lack of training \& trained staff. } \\
\text { Lack of evidence for the value. } \\
\text { Limited interaction between basic } \\
\text { teachers and clinicians. } \\
\text { Faculty time limitation. } \\
\text { Lack of research \& publication. }\end{array}$ \\
\hline $\begin{array}{l}\text { Using student- } \\
\text { centered } \\
\text { instructional } \\
\text { strategies }\end{array}$ & $\begin{array}{l}\text { Lack of trained faculty } \\
\text { Students' resistance to new } \\
\text { instructional strategies. } \\
\text { Resource constrains. } \\
\text { Faculty interest. }\end{array}$ \\
\hline
\end{tabular}

\section{DISCUSSION}

Introduction of modular system through integrated curriculum in all medical colleges of Pakistan is mandatory as per PMDC; so it is institutional requirement for its accreditation to initiate integrated curriculum and make necessary arrangements for its implementation. This study presented the mixed views of basic sciences faculty's perceptions regarding curricular integration, with major concerns for its appropriate implementation. Majority of basic sciences faculty respondents expressed interest in enhancing the integration of the institution's curriculum with some concerns. There is a growing consensus that both basic sciences and clinical faculty recognize the need for greater health education integration ${ }^{1,11-13}$.

It is a fact that teachers especially basic faculty face challenges in dealing with curricular changes; hence it is important to understand their perception of the success of reforms ${ }^{14}$. The change is demanding, particularly for basic science teachers who specialize in one subject for teaching, but are now expected to create integrated learning opportunities by connecting a 
number of subjects ${ }^{15}$. Awareness of integrated curriculum is there and most of them are agreed about the benefits of curricular integration. However there are still some reservations about design, planning, implementation and time limitations of the integrated curriculum. Dashputra et al reported 92\% awareness of integrated curriculum which is similar to our study ${ }^{6}$. hers in our study about adequate distribution of topics of basic sciences in integration.

Integrated curriculum is an effective way to teach $21^{\text {st }}$ century capabilities and engages students in learning ${ }^{17}$. More than ninety percent teachers are agreed that students' engagement in learning, similar to the finding noted by Basu et al in India ${ }^{16}$. Engaging the

Table-IV: Major themes generated with some verbatim quotes.

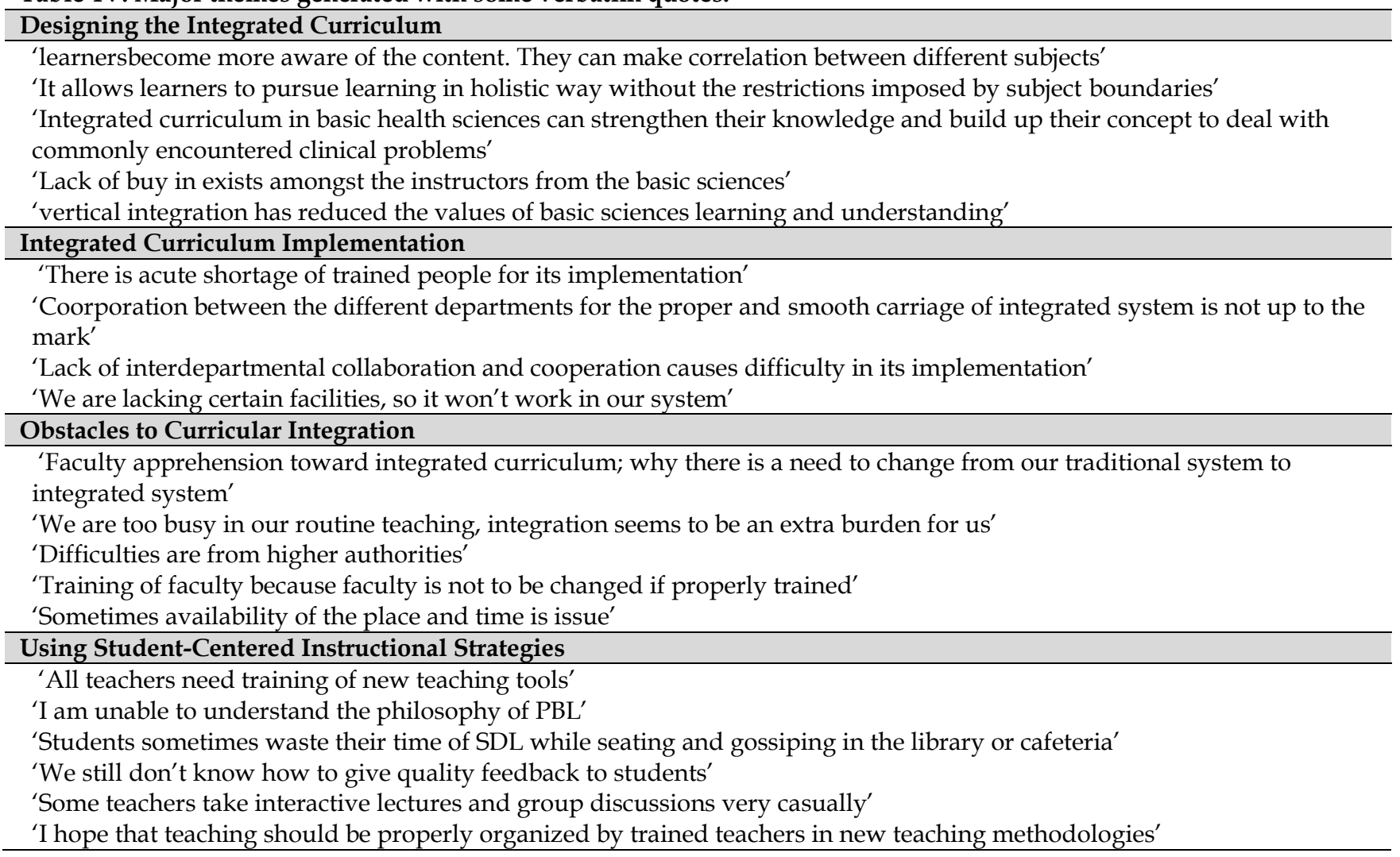

Majority $(82 \%)$ of the teachers in our study agreed that introduction of integrated curriculum resulted in relevant learning experiences and facilitated higherorder learning. This is contrary to the findings of Chan et al who identified that only $41.6 \%$ of the teachers believed curriculum integration benefit learning experiences $^{14}$. Khalil et al also reported that majority of teaching faculty was of opinion that integrated curriculum was relevant and important to students' learning4.

Recently medical educationists realized that there is a need for integrating basic and clinical medical sciences ${ }^{16}$. There is little disagreement that both sciences are important; 8 however timing of integration, distribution of content of both sciences, availability of teaching tools and coordination of disciplines influence its implementation. There were mixed views of teac- students frequently is emphasized for effective curriculum and instruction. Further faculty think students are more comfortable with integrated curriculum ${ }^{10}$.

Medical education advocates relevant, purposeful and meaningful learning experiences; hence proper planning of integration of curriculum is required to achieve this objective ${ }^{18}$. Our basic sciences faculty also showed concerns for planning and design of integration. Khalil et al stressed that a lot of work on the part of planners is required to educate experts on the topic of the program objectives and how to achieve them ${ }^{4}$. Driving the social advocacy, designing a learner-centered integrated curriculum is required. According to Quintero et al, vertical integration would involve not only basic and clinical sciences, but also socio-humanistic and public health sciences, contributing to a wider understanding of how to practice and learn medicine ${ }^{19}$. 
There is a clear evidence that shows the prevalence of strong concerns regarding implementation of integrated curriculum ${ }^{21}$. Faculty highlighted some important obstacles in implementation of integrated curriculum in this study. These are faculty resistance, crossing of disciplinary boundaries, lack of trained staff, limited interaction between basic teachers and clinicians, faculty time limitation and deficient research. A well-approached change process is required for the successful implementation of integrated curriculum especially ownership and a strong political will ${ }^{21}$. Studies identified fear of the unknown, fixed mindset, more constraints to get out of discipline comfort circle as being a major factor of faculty resistance preventing the teachers from achieving the intended benefits ${ }^{22}$. Such statements result in a slow process and lead to misunderstandings. In our research, the same pattern has been observed that the faculty has struggled to find acceptance of integration due to their busy work schedules or denials, which increase the pressure of learning for students. There is a need of effective efforts for overcoming obstacles to curriculum integration like faculty development, an interdisciplinary approach, building competencies and making assessment tools ${ }^{23}$.

Familiarity of new instructional strategies is another subject of concern for researchers ${ }^{24}$. Lack of trained faculty, students' resistance to new teaching tools, resource constrains and faculty interest are identified in this study. Almost similar results are reported in another study ${ }^{25}$. Hence it is difficult to proceed with curriculum integration without faculty training, ownership of integrated curriculum with collaboration of basic and clinical sciences teachers.

\section{CONCLUSION}

Curriculum integration is beneficial and essential for student's learning but needs proper planning and implementation. It is recommended that more work tackle current negative perceptions and seed practical solutions to their challenges.

\section{CONFLICT OF INTEREST}

This study has no conflict of interest to be declared by any author.

\section{REFERENCES}

1. Pearson ML, Hubball HT. Curricular integration in pharmacy education. Am J Pharma Edu 2012; 76(10): 204.

2. Muller JH, Jain S, Loeser H, Irby DM. Lessons learned about integrating a medical school curriculum: perceptions of students, faculty and curriculum leaders. Med Educ 2008; 42(8): 778-74.

3. Vergel J, Stentoft D, Montoya J. Extending the theoretical framework for curriculum integration in pre-clinical medical education. Perspect Med Educ 2017; 6(4): 246-55.
4. Khalil MK, Kibble JD. Faculty reflections on the process of building an integrated preclerkship curriculum: a new school perspective. Adv Physiol Educ 2014; 38(3): 199-209.

5. Papa FJ, Harasym PH. Medical curriculum reform in North America, 1765 to the present: A Cognitive Science Perspective. Acad Med 1999; 74(2): 154-64.

6. Dashputra A, Kulkarani M, Chari S, Manohar T. Perception of medical teachers toward present day medical education. Int J Educ Sci 2012; 4(2): 91-95.

7. Ali SK, Baig LA. Problems and issues in implementing innovative curriculum in the developing countries: the Pakistani experience. BMC Med Educ 2012; 12(1): 31.

8. Bandiera G, Boucher A, Neville A, Kuper A, Hodges B. Integration and timing of basic and clinical sciences education. Med Teach 2013; 35(5): 381-87.

9. Waqar SH. Student's perceptions of direct observation of procedural skills as workplace based assessment tool in general surgery. Pak Armed Forces Med J 2016; 66(5): 731-37.

10. Kayani ZA, Gilani I, Mahboob U. Perceptions of medical teachers about integrated curriculum: A qualitative study. J Ayub Med Coll Abbottabad 2018; 30(3): 381-85.

11. Quintero GA, Vergel J, Arredondo M, Ariza MC, Gómez P, Pinzon-Barrioset AM. Integrated medical curriculum: advantages and disadvantages. J Med Educ Curric Dev 2016; 3: 133-37.

12. Vidic B, Weitlauf HM. Horizontal and vertical integration of academic disciplines in the medical school curriculum. Clini Anatomy 2002; 15: 233-35.

13. Tresolini CP, Shugars DA. An integrated health care model in medical education: interviews with faculty and administrators. Acad Med 1994; 69(3): 231-36.

14. Chan CK. Faculty perspectives on the " $3+3+4$ " curricu-lum reform in Hong Kong: a case study. Int Educ Stud 2013; 6(4): 56.

15. Niemelä MA. Teachers' knowledge of curriculum integ-ration: A current challenge for Finnish subject teachers. In: Wein-berger $Y$, Libman Z, editors. Contemporary Pedagogies in Teacher Education and Development. London: Intech Open; 2018. pp. 119-132.

16. Basu M, Das P. Introducing integrated teaching and comparison with traditional teaching in undergraduate medical curriculum: A pilot study. Med J DY Patil Univ 2015; 8: 431-38.

17. Drake SM. Integrated curriculum as an effective way to teach $21^{\text {st }}$ century capabilities. Asi Pacific J Edu Res 2018; 1(1): 31-50.

18. Atwa HS, Gouda EM. Curriculum integration in medical education: a theoretical review. Intel Prop Rights 2014; 2: 113.

19. Quintero GA, Vergel J, Arredondo M, Ariza MC, Gómez P, Pinzon-Barrios AM. Integrated Medical Curriculum: Advantages and Disadvantages. J Med Educ Curric Dev 2016; 3: S18920.

20. Hopkins R, Pratt D, Bowen JL. Integrating basic sci-ence without integrating basic scientists: reconsidering the place of individual teachers in curriculum reform. Acad Med 2015; 90(2): 149-53.

21. Arja SB, Arja SB, Venkata RM, Nayakanti A, Kottathveetil P, Acharya $Y$. Integrated curriculum and the change process in undergraduate medical education. Med Teach 2018; 40(5): 437-42.

22. Khan A, Asher A, Ahmad A. Frame factors for implementation of integrated curriculum in public sector medical college-Faculty's perspective. Pak Armed Forces Med J 2016; 66(6): 891-97.

23. O'Keefe M, Ward H. Implementing interprofessional learning curriculum: how problems might also be answers. BMC Med Educ 2018; 18(1): 132.

24. Anwar MI, Kiani JA, Nadeem N. Integrated medical curriculum: design, delivery and assessment during first two years of medical education-a review at AJK Medical College, Muzaffarabad, Pakistan. Pak J Med Health Sci 2018; 12(4): 1591-95.

25. Kadirvelu A, Gurtu S. Integrated learning in medical education: are our students ready? Med Sci Educ 2015; 25(4): 549-51. 